To the Proceedings of the Academy of Sciences of Philadelphia for October, I9 10, Dr. H. W. Fowler contributes notes on little-known New Jersey fishes, and likewise notes on various chimæroids and ganoids. In the latter a new chimæra is described from New Zealand, and two new species of Cylindrosteus are likewise named.

In the same serial for December, I910, Mr. Burnett Smith describes certain fish-remains from the Devonian of New York. Most of these are species pertaining to the European genus, Machæracanthus; but the author was fortunate enough to obtain part of the armour of a small arthrodire, which is provisionally regarded as referable to the plastron of a species of Dinichthys. Assuming this to be the case, he points out that the generally received determination of the bony elements of this part of the exoskeleton is incorrect.

In Science Progress for January, Dr. H. H. Swinnerton gives reasons to show that the ordinary view as to the respective functions of the median and paired fins of fishes require revision. These views are based, at any rate to a considerable extent, on the movements of fishes which have been deprived of one or more of their fins; but the author points out that operations of such severity must have caused very serious shock to the patients, and thus induced "wobbling" and other eccentric movements. As regards the hind dorsal and the ventral fin, the author is of opinion that their function is connected with the tail-fin, which is the sole propelling organ of the fish. The anterior dorsal fin, on the other hand, appears to serve as the chief agent in the rapid turning movements which are essential to the safety of a fish living in swiftly flowing waters. As regards the functions of the paired fins, these appear to have changed pari passu with the modification in the structure and orientation of these appendages which has taken place as we pass from ancient generalised to modern specialised types. To follow the author in tracing these out would, however, occupy too much space on the present occasion, and it must suffice to state that whereas in the primitive fossil shark Cladoselache the paired fins were little more than broad-based lobes on the sides of the body, with their expanded surfaces in the plane of the latter, in modern teleost fishes they are narrow-based fan-like structures, with their broad surfaces capable of being extended at right angles to the axis of the body. And the author has found that " it is possible to recognise a complete sequence from the broad-based fin acting as a keel, through the narrowbased fin with limited freedom acting as a lateral rudder, to the narrow-based fin with great freedom of movement which enables it to be used either as a keel, a lateral rudder, or a break."

In the April number of The Zoologist Colonel $\mathrm{C}$. $\mathrm{E}$. Shepherd continues his account of the pharyngeal teeth of fishes, dealing in this instance with the members of the cod family (Gadidæ) and the Carangidæ.

R. L.

\section{TECHNICAL TRAINING AND THE OPTICAL INDUSTRY.}

THE scheme for the establishment of an Institute of Technical Optics in London was described in a short article in the issue of NATURE for March 16. In that article reference was made to two elaborate reports, covering nearly forty pages of foolscap print, and signed, respectively, by the education officer of the London County Council, Mr. R. Blair, and the Council's educational adviser, Dr. Garnett. The contents of Mr. Blair's report provide much information as to the provision made in this and other countries for higher work in technical optics, and we here reprint extracts from this report as showing the need for the action of the London County Council.

Introduction.-Although the United Kingdom is no longer in the forefront of the optical industry, the science of optics stood on a high level in this country for about 140 years after the publication of Newton's "Treatise on Optics" in I704. Since I850, however, the study of geometrical optics has progressed rapidly in Germany, but has been practically at a standstill in England. The trade conditions in both countries have kept pace with the state of optical knowledge. At one time the Uniter Kingdom NO. 2 I65, VOL. 86$]$ made most of the best optical instruments in the world and produced a large proportion of optical inventions. But latterly, inventions, presumably owing to more improved facilities for study and practical training, have been more numerous in Germany than in the United Kingdom. The great increase in the German production and export has also been assisted by many other factors, amongst which may be mentioned the help afforded by the Imperial Physical-Technical Institute at Charlottenburg (which should not be confused with the Technical University at the same town), the efforts of the Association of Instrument Makers, and the perfection to which the production of the special glass required has been brought at Jena. During the last fifteen years it has been gradually recognised in England that if the lost ground is to be regained, either wholly or partially, adequate provision must be made for optical instruction in all its branches.

A large amount of valuable information had been gradually gathered together, but, in view of the considerable expenditure suggested in aid of technical training for the optical industry, the presentation of this report was postponed until all available sources of information could be consulted. The inquiries include information regarding the extent of the trade in London and the provinces; the amount of capital invested and the number of workmen employed; the amount of imports and exports; any pecuniary support likely to be forthcoming from the trade or other sources, and the extent to which the trade would cooperate both in giving facilities to employees to attend the proposed institute, and in other ways: the question as to what branches of the optical industry should be included in the scheme, and the nature and extent of the institute as regards accommodation, equipment, and staff. It has also been necessary to study carefully the conditions of optical instruction and trade in Germany, and to investigate the statements and representations on behalf of their interests made by persons and bodies interested in the science of optics and the manufacture of optical instruments in England.

The final results of the investigations made and the conclusions which may reasonably be drawn from them taken as a whole, point to the necessity for the establishment of the proposed institute for industrial, scientific, and national reasons-industrial because of the lack of progress in the British optical industry compared with the rapid progress made in Germany, and the fact that the value of an optical instrument lies almost wholly in the scientific knowledge and skilled labour applied to its making; scientific because of the necessity to the scientific worker of the production on the spot of the best and most suitable instruments for the purposes of pure and applied science; national because of the necessity of the home production of instruments for various branches of the public service.

\section{Comparison between the Provision of Optical} Instruction in England and Germany.

It appears beyond doubt that instruction in pure and applied optics and in fine instrument making is much more developed in Germany than in England. At most German universities, especially the technical universities, the importance of optics and its practical applications are recognised to a greater extent than in England; in some cases attention is even devoted to the practice of instrument making. At English universities optics are either practically neglected or are taught as a branch of physics together with sound, heat, and electricity. When attention is devoted to optics, the practical application of optical principles to the designing of instruments is almos entirely disregarded.

With regard to special technical schools for instrument making, Germany possesses four, England only a depart. ment of an institute. Moreover, the German schools are generally housed in proper buildings and well equipped for theoretical and practical work, whilst the building and equipment of the Northampton Department of Optics are quite inadequate.

The attention devoted to the German schools is reflectei in the attendance of full-time day pupils:- Schwenningen, for example, has seventy-two, Göttingen eighty-eight, of whom a large number are engaged in technical optics. The department at the Northampton Institute has twenty 
students, most of whom are engaged in sight testing and spectacle making and not in optical instrument making. The liberal funds available for the German schools enable them to charge only about 305 . per annum for full-time instruction. The Northampton Institute is compelled to charge $x_{5} l$. per annum, a fee which many students must find it impossible to pay.

It is of some importance to observe that the four German schools, as their names imply, are organised for the teaching of fine instrument making generally, whereas the Northampton department is principally concerned with optical instruments.

Finally, it may be noted that the German schools have been established by the municipalities concerned, generally as a result of action taken by the local trades. They receive, however, maintenance grants from the States concerned and appear to be in close touch with the authorities.

The single courses given in fine instrument making at various German trade schools are at least equal in organisation and quality to the one or two courses at technical colleges in England and are greater in number. The work of the Munich course has been developed to that of a department of technical optics; 20 I pupils receive eight to nine hours' instruction per week.

The more numierous and superior opportunities for optical instruction in Germany have made themselves felt in all directions. Formerly a large number of optical inventions were made in England. Latterly, they have been more frequent in Germany, and the resulting trade has gone to that country. The records of the Patent Office are conclusive in this respect; such names as Zeiss, Goerz, Anschütz, Steinheil, Busch, \&c., are household words in British optical circles. Some British firms are compelled to employ foreign mathematicians.

No practical text-book of optics exists in English, and the principal technical literature on the subject of optical progress and inventions is in German. The Northampton Institute is the sole place in England where the Gauss system of computing simple lenses and lens systems is properly taught. English optical instrument makers who wish to keep abreast of their science and industry are compelled to learn German and teach themselves.

In spite of these drawbacks, many important recent in ventions have been made in England; in fact, as regards the quality, the English optical inventions are probably unrivalled, although in quantity they are less. As British enterprise and manual skill are not inferior to German, it is reasonable to suppose that this country would easily hold its own if the necessary opportunities for full instruction were provided. In former times optical problems were simpler and technical methods less complex. This has entirely changed, and to-day Germany, the country with the best optical literature and instruction, produces most inventions and has the biggest output and export.

In spite of the advances made in optical instruction in Germany, it does not appear that the optical trade is by any means content with what has been done. The instrument making schools are being improved and expanded, and trade classes for instrument-making at other technical schools are being increased and developed. To give two recent examples-the Göttingen school has just moved into a new building, and the Munich course has been converted into an independent department. Technical optical lectures are increasing at technical and older universities. There is a strong feeling that much more could be done by the State and municipalities for the further advancement of technical optics. This is very significant in view of the fact that the British industry at present is pressing for only a part of the educational facilities already at the disposition of the German industry.

Comparison between the Extent of the British and German Optical Industries.-Germany, the country with the most numerous and best-equipped schools, departments, and courses for teaching instrument making, and with the best technical universities, has captured the largest amount of the world's optical trade. Starting well behind France and England, she has thoroughly beaten both countries in the amount of her production and export. In both countries there is considerable difficulty in obtaining trustworthy figures as to capital and the number of workmen employed. Fairlv definite figures, however, can be obtained

NO. 2 I65, VOL. 86] from the export and import results and the British census of production figures.

The net British exports of scientific instruments, \&c. have only increased from $395,009 l$. in 1900 to $509,185 l$. in 1909. But at the same time there has been a heavy import, commencing at $595,305 l$. in 1900 and rising to $666,563 l$. in 1909 .

The German export of scientific instruments, \&c., was valued at $1,200,000 l$. in 1898 , and for 1909 it was valued at $2,276,550 l$. Since 1004 alone it has increased by $776,550 l$. Imports into Germany appear to be very low, whilst in England the imports are so heavy as to be larger than the exports. At the present moment the German export of optical instruments is almost as great as the whole of the British production. Apparently the British trade has no true exports in the sense of excess of exports over imports, and is dependent upon foreign imports for a part of the home consumption. In spite of all these disadvantages, however, the British industry continues to exist and do excellent work. The Germans state that at the Brussels Exhibition, rgro, both the British and French industries were well represented, and they direct special attention to the large English catalogue with its good illustrations.

Germany and France appear to possess almost a monopoly in the production of the special glass required for optical instruments; the French glass is made from German formulæ. Large quantities of raw optical glass and of partially and fully finished glasses and lenses are annually exported to England. If this export were interfered with by any cause, a large section of the British industry might possibly find itself in a very grave position.

It is not technical education alone which has assisted the German industry. There has evidently been a keen demand for the finest instruments of precision made in the country itself on the part of men of science, professors, professional men, the army, the navy, and manufacturers. Great help has also been afforded by the following factors:-

German Association of Instrument Makers.-The association was founded in $188 \mathrm{I}$. It looks after the interest of the trade in every respect with regard to general education technical training, commercial education, international and other exhibitions, and finally by representations to the Imperial Government. This last point seems of some importance, and some details may therefore be given. It appears that, as far back as 1800 , the association was agitating for the proper differentiation, in official documents, between optical and other fine instruments. The difficulties caused by the lack of a suitable scheme of classification have already been mentioned. At the same time the association was making representations against a protective tariff for instruments manufactured in Germany, as their second market lay in foreign countries, and reprisals were feared. Other negotiations have been carried on with the Government with regard to avoiding the duties paid on the re-import of instruments for purposes of repair. This is most significant, as it shows that instruments sold abroad cannot be repaired abroad, but have to be returned to Germany for this purpose. The association deals very fully with all questions regarding the participation of German firms in international exhibitions and with representations concerning the imposition of foreign tariffs on German goods. In one case it approached the Danish Government with reference to obtaining a larger amount of Iceland spar for optical purposes.

Jena and the Optical Industry.-Much of the success of the German industry comes from the town of Jena, where the firm of Zeiss is situated. Three men combined togethe in order to produce what was required for the optical industry. These were Dr. Schott, a glass manufacturer; Prof. Abbe, an oculist; and Carl Zeiss, a microscope maker. Prof. Abbe's efforts have had great influence upon the German industry. He introduced many improvements, and endeavoured not only to benefit his own firm but the whole industry. Dr. Schott obtained a grant from the Prussian Government for the purpose of investigating the best kinds of glass for optical purposes, especially with regard to the relation between the optical properties of glass and the chemical composition of solid amorphous fluxes. The result is that Schott has almost a world'c monopoly for the best kind of special glass for optical purposes. Where one of the "ery few English glass manu- 
facturers will quote at most about twenty-five different meltings, Schott of Jena, and Parra-Mantois of Paris will quote anything between 100 and 150 . It may be mentioned that the University of Jena has benefited to the extent of about $100,000 l$. by the success of the firm of Zeiss. At the present time the firm of Zeiss employs about fourteen graduates who are either mathematicians or medical men.

Imperial Physical-Technical Institute.-Very great assistance has been rendered by the Imperial Physical-Technical Institute in Charlottenburg, which, as above mentioned, should not be confused with the Technical University in the same town. It was founded in 1887 , and is concerned partly with physical research and partly with the development, standardising, and testing of fine instruments of almost every description. Its relations to the optical industry are numerous and intimate, and the manufacture of optical instruments has benefited accordingly.

The British Optical Society.-Some account may be given of the Optical Society on account of its relations to the optical department at the Northampton Institute and the trade generally.

The society was founded in 1899 , and has over 400 members in London and the provinces at the present time. It has kept alive the interest of the different branches of the trade in the technical optics classes at the institute, and has for a series of years contributed about irol. per annum towards the expenditure for the same.

It has also been instrumental in placing the trade in communication with the institute with regard to the details of optical work. In rgor it appointed an educational committee for the purpose of inquiring into the question of optical education generally. In 1902 Prof. Silvanus Thompson read an important paper on "Technical Optics" before the Society of Arts, in which he strongly urged the establishment of a real optico-technical institute either at the Northampton Institute or elsewhere. The same conclusion was arrived at by the Education Committee of the Optical Society. The committee pointed out that it was only by the provision of such educational facilities that the optical trade of this country could be expected to compete with its foreign rivals, and that the Northampton Institute, with its teaching staff and equipment, would be the suitable place for the new optico-technical institute.

The German industry has received much more benefit from its association than the British industry from the corresponding association in England. Finally, as the German research and standardising institute at Charlottenburg came into existence long before the corresponding English institute, it has consequently been enabled to get into closer and more fruitful touch with the optical industry.

The Optical Convention in 1905.- The convention deal not only with scientific and trade subjects, but devoted considerable attention to the problem of optical education. On this last point it adopted the following resolution :-

"That the Optical Convention hereby expresses the cordial approval of the project of founding an optical technical institute for the training of opticians in the scientific principles of optics and their technical applications which it regards as a matter of industrial importance to the nation; and in view of the backward state of optical teaching in this country it urges the London County Council to push forward, as a matter of pressing need, the foundation of such an institution on the lines of the scheme which was under the consideration of the late Technical Education Board."

\section{The Paramount Importance of the Optical Industry for}

Industrial, Scientific, and National Purposes.

It may be urged that the expenditure contemplated (amounting to $35,000 l$., together with an annual maintenance grant rising eventually to $5000 l$.) is comparatively large in proportion to the extent of the optical industry, its capital, number of employees, and production. But this objection can scarcely be maintained when the problem is studied in all its far-reaching aspects.

In the first place, there are very few industries where the ultimate value of the goods produced represents so much in wages for the skilled designers and workmen and so little in the actual scrap-value of the materials employed.

NO. 2 I65, VOL. 86$]$
It is difficult to find an exact parallel in other branches of manufacture. For example, the production of valuable chemical products from certain raw materials as the result of intricate investigation and a long series of reactions. Or, perhaps the case of artistic products in which the actual value of the materials is very little compared with the value conferred by the insight of the artist and the cunning of his hand.

The overwhelming importance of the optical industry on the larger scientific and national issues involved was very clearly stated by Mr. Conrad Beck on the occasion of the deputation of the optical industry to the Technical Education Board in I902. He pointed out that the number of instruments, for the manufacture of which optical knowledge is required, was very great indeed, ranging from ordinary spectacles, opera glasses, field glasses, telescopes, nautical instruments, microscopes, photographic lenses, photographic apparatus, and so forth, to surveying instruments, astronomical instruments, lanterns, range finders, gun sights, lighthouse prisms and reflectors, heliographs, periscopes, and almost every kind of optical instrument.

These instruments are widely used in the prosecution of science, in industrial processes, in the exercise of many important professions, in our shipping trade, the greatest in the world, and in the nation's naval and military lines of defence.

It cannot be too clearly understood that the success of the manufacture of all the instruments mentioned depends upon a thorough knowledge of practical optics on the part of designers and managers, and upon a constant supply of skilled foremen and workmen.

In times of peace the War Office and the Admiralty probably require something like 25,000 field glasses and telescopes per annum, and much larger number in times of war; the numbers sold to private individuals are, of course, much greater. Both the War Office and the Admiralty have been approached with regard to the influence which the proposed optical institute will have upon the production of the finest kinds of optical instruments used in the army and navy.

Spectacles, sooner or later, are worn by large numbers of persons. Field glasses and telescopes alone constitute a large business. All medical, biological, and many other students require microscopes; every ship's officer requires a sextant. Engineers require large numbers of levels and theodolites. The number of photographic lenses sold annually is extremely large. The illustrations of magazines, newspapers, and the majority of books are produced by photographic printing processes, largely depending for success on optical principles.

The advent of long range guns has been responsible for a special section of the optical industry concerned with the manufacture of elaborate optical gun sights and special telescopes of peculiar construction; new methods for range finding by optical instruments are being constantly sought.

In various industries a microscope is becoming each year of greater importance. It is used in the testing of steel and iron and for brewing, butter making, silk and textile manufacture, sugar making, and in numerous other industries. The photographic industry alone, which has assumed such great dimensions during recent years, is entirely dependent upon optical principles. Although large amounts of chemicals are used in photography and various materials for the construction of cameras, all the work employed would be entirely useless without the proper designing of the lenses employed.

Finally-although it cannot be definitely stated in concrete terms-there would appear to be some relation between the general efficiency of a nation and its manufacture of the finest instruments of precision for purposes of observation, research, measurement, and control. The material development of a nation is largely concerned with the utmost utilisation of the natural forces and materials at its disposal, and both pure and applied science are becoming increasingly dependent upon the help afforded by the finest instruments. A nation should have for this purpose an ample supply of the finest instruments. It should manufacture these itself for its own special purposes, and keep itself in a condition to repair and improve existing instruments and invent and construct new ones. It is significant to observe that both England and France have fallen behind Germany in this respect. 
Final Remarks and Recommendations.

I have no hesitation in stating that a case has been made out for the establishment of the institute on broad and comprehensive lines, an institute which shall not only serve the needs of London, but also be of use to everyone connected with optical matters in the United Kingdom. The state of the industry, scientific opinion, and the other considerations involved, point to the need of the establishment of an institute without further delay. At the present moment an opportunity is afforded for utilising to the full the experience gained in foreign countries, the optical instruments of which have, to a large extent, supplanted our own. The Optical Institute, if founded, might become, under proper management, the first of its kind in the world. The material for doing this is at hand; it should be remembered that even in its present incomplete condition the optical department of the Northampton Institute has been visited by foreign technical experts, and many of its leading features copied.

The investigation has shown that the widest cooperation may reasonably be expected from eminent men of science, from the leading manufacturers, and from the University of London, other universities, and the Imperial College. The institute is thus assured of the best scientific advice possible and of actual practical help from interested manufacturers, and it will benefit by being linked up with institutions of university rank for the purposes of the finest research directly applicable to practical and industrial purposes.

The principal decision to be arrived at by the subcommittee at the present stage is whether capital expenditure, amounting to $35,000 l$., and an annual maintenance grant rising eventually to $5000 \mathrm{l}$., for the benefit of the optical industry is justifiable, bearing in mind the great national and industrial issues involved. Most of the further details must be considered later and must form the subjects of special reports. Such details will include the proportion of instruction to be devoted to optical instruments in particular and to other fine instruments of precision, the final arrangement of the rooms, details of staffing, the nature of the equipment, the prosecution of research in optical instruments and in optical glass, and so forth. A sum of $5000 l$. in respect of the contemplated expenditure has been included in the capital estimates for I9II-I2, and I recommend:-

(I) That a grant of $35,000 l$, including $5000 l$. for equipment, be allowed to the governors of the Northampton Polytechnic Institute (Finsbury, C.), in respect of an institute for technical optics as set forth in the foregoing report.

(2) That the institute be built upon the site already purchased by the governors of the Northampton Polytechnic Institute.

(3) That the institute be governed by the governing body of the Northampton Polytechnic Institute.

(4) That a consultative committee be formed for advisory purposes, on which the optical trade shall be adequately represented.

(5) That, for research and other purposes, steps be taken to affiliate the institute to the Imperial College of Science and Technology, and to associate it closely with the National Physical Laboratory at Teddington and institutions of university rank.

\section{UNIVERSITY AND EDUCATIONAL INTELLIGENCE.}

ANNOUNCEMENT of generous bequests to Aberdeen University is made in The Times. From this source we learn that the late Miss Anne Hamilton Cruickshank, daughter of the late Prof. John Cruickshank, who held the chair of mathematics in Aberdeen University, has provided by her will for a professorship or lectureship in astronomy, including navigation and meteorology, in the University, and for a science library at Marischal College. Miss Cruickshank bequeaths Io,oool., from which the trustees are to apply such amounts as, with the funds already in their hands for the same purpose, will make up a total of $10,000 l$. for the institution and endowment of a lectureship or chair of astronomy, including navigation and meteorology. Any balance of the 10,0ool., after deduction NO. 2 I65, VOL. 86] of the sum required for the institution of a chair of astronomy and the cost of the windows, is to be set aside and applied in such manner as the special trustees may think proper for the library at Marischal College. Miss Cruickshank also leaves $10,000 l$. to the special trustees for the founding and supporting in Marischal College of a science library, to be called the Cruickshank Science Library.

LADY Kelvin has made a gift of 500l. to the University of Glasgow for the purpose of founding therein a prize for original research in physics, in memory of the late Chancellor. The prize, which will be accompanied by a gold medal, will be awarded once in three years to a doctor of science who has graduated in the interval, and whose dissertation contains evidence of original experimental work deserving of this special distinetion. A similar prize was recently founded by the pupils and friends of Prof. William Jack, to be awarded for the most distinguished mathematical thesis offered for the degree of D.Sc.

AT a meeting or members and officials of local education committees, held at Aberystwyth on April 18 in connection with the Conference of the National Union of Teachers, a discussion upon the necessity for further financial aid for education from the central exchequer was opened by a paper read by Mr. G. S. Baxter, secretary of the Sheffield Education Committee. The following facts from Mr. Baxter's paper are of interest. For the year 1904-5, the expenditure of local education authorities on current account for all purposes pertaining to elementary education only was 184 millions, towards which Government grants of $9^{4}$ millions were received, whilst for the year 1908-9 (the latest available official returns) the expenditure of local authorities had increased to 23 millions and the Government grant to $I_{\frac{2}{3}}^{2}$ millions. Therefore, although local charges increased by $4 \frac{1}{\mathrm{~g}}$ millions in four years, the State contribution only advanced by about $I \frac{1}{2}$ millions. In addition to the added responsibilities in respect of elementary education, the cost of supplying and aiding secondary, technical, and higher education for the year ended March 3I, I909, amounted to $4^{\frac{2}{2}}$ millions, towards which Government grants were received amounting to less than 2 millions. Taking elementary, secondary, technical, and higher education together, therefore, local authorities in England and Wales expended in 1908-9 a total sum of $27 \frac{1}{2}$ millions, of which the Government contributed just over. ${ }_{3}$ millions, or 48 per cent., leaving about $14 \frac{1}{2}$ millions, or $5^{2}$ per cent., of the amount to be provided locally.

AT the Aberystwyth Conference of the National Union of Teachers, the following resolution, proposed on behalf of the executive, was adopted:-." This conference is of opinion that (a) no exemption (either partial or whole time) from school attendance should be granted until the age of fourteen years is attained; $(b)$ all wage-earning child labour out of school hours under the age of fourteen should be forbidden by law; (c) a system of compulsory attendance at continuation schools from the age of fourteen to eighteen, accompanied by provisions which should safeguard the young people against undue physical or mental overstrain, should be an integral part of a national system of education; $(d)$ it should be the statutory duty of the local education authority of each county and county borough to make suitable provision for such further education; (e) it should be the statutory duty of every employer of any young person under eighteen years of age (I) to enable him or her to attend continuation classes for such periods of time and at such hours as may be required by the Act, and (2) to supply the names of all such young persons to the local authority on demand; $(f)$ all employers should be forbidden under penalty to employ or continue to employ any young person under eighteen years of age who failed periodically to produce a card attesting his or her attendance and good conduct at continuation classes or other educational institutions in conformity with the Act; (g) it shall be the duty of the State to make provision for the maintenance of any young person who may be deprived of the means of living as a result of the operation of any national system of education such as is outlined in the foregoing resolutions." 